Electronic Physician (ISSN: 2008-5842)

http://www.ephysician.ir

July 2017, Volume: 9, Issue: 7, Pages: 4862-4871, DOI: http://dx.doi.org/10.19082/4862

\title{
A Novel Therapy for cocaine dependence during abstinence: A randomized clinical trial
}

\author{
Bijan Pirnia ${ }^{1}$, Ali Reza Moradi ${ }^{2}$, Kambiz Pirnia ${ }^{3}$, Parisa Kolahi ${ }^{4}$, Rasool Roshan ${ }^{5}$
}

${ }^{1}$ Ph.D. Student of Clinical Psychology, Department of Psychology, Faculty of Humanities, University of Science and Culture, Tehran, Iran

${ }^{2}$ Ph.D. of Psychology, Professor, Department of Psychology, Faculty of Humanities, Kharazmi University, Tehran, Iran

${ }^{3}$ M.D., Internal disease specialist, Technical Assistant in Bijan Center for Substance Abuse Treatment, Tehran, Iran

${ }^{4}$ Ph.D. Student of Psychology, Department of Psychology, Islamic Azad University, Central Tehran Branch, Tehran, Iran

${ }^{5}$ Ph.D. of Psychology, Professor, Department of Psychology, Faculty of Humanities, Shahed University, Tehran, Iran

\section{Type of article: Original}

\begin{abstract}
Background: Topiramate is an anticonvulsant drug and an ideal candidate for reducing the craving in people relying on cocaine. Contingency management is one of the common therapies in the domain of addiction.

Objective: The present study aimed to evaluate and compare three medication methods of Topiramate (TPM), Contingency Management (CM) and the combined TPM treatment and cash intervention on craving during abstinence.

Methods: This randomized clinical trial was conducted at Bijan Center for Substance Abuse Treatment in Tehran, Iran, from December 15, 2014 to November 20, 2015. One hundred males (Age range=18-34; SD=4.11) undergoing abstinence were assigned randomly to four groups $(n=25)$ of Topiramate (TPM), Contingency Management (CM) and the Combined Method plus a placebo control group. Treatment was provided for twelve weeks for the experiment groups, and only the control group received the placebo. Participants in the Cash-based and CM Condition had an identical 12-week escalating schedule of reinforcement (cash-based incentives worth $\$ 0, \$ 20, \$ 40$, and $\$ 80$ ). Also, in the Topiramate group, participants' dosage ranged between $25-300 \mathrm{mg} /$ day in escalating doses) $25,50,100,150,200,250,300$ ). In addition, all subjects received brief behavioral compliance enhancement treatment (BBCET). Participants took a urine test twice a week, with a given threshold of $>300$ $\mathrm{ng} / \mathrm{ml}$, and indicators of cocaine craving (response rate $=91 \%$ ) was evaluated in two phases of pre-test and posttest. We used Chi square, ANCOVA Univariate Model and Scheffe's post hoc to analyze the primary and secondary outcomes. Also, the qualitative data resulted from demographic evaluations were coded and analyzed by the instrument of analysis of qualitative data i.e. Atlas.ti, Version 5.2.

Results: The results showed that all three types of treatment played a significant efficacy in reducing the craving. The mean $(95 \% \mathrm{CI})$ scores of craving was $12.04(\mathrm{p}=0.05)$ with TPM, $13.89(\mathrm{p}=0.05)$ with $\mathrm{CM}, 10.92(\mathrm{p}=0.01)$ with Mix and $16.89(\mathrm{p}>0.05)$ with control. Moreover, the highest variance explaining the changes in craving was assigned to the combined treatment $(\mathrm{p}<0.01)$.

Conclusions: The findings of this study, while having applicable aspects in this domain, can be helpful in planning supplementary remedial procedures.

Trial registration: The trial was registered at the Thai Clinical Trial Registration Center with the TCR ID: TCTR20170112001.

Funding: The authors received no financial support for the research, authorship, and/or publication of this article.

Keywords: Topiramate, Contingency Management, Craving, Anticonvulsants/adverse effects, Pharmacotherapy, Cocaine Dependence
\end{abstract}

\section{Corresponding author:}

Bijan Pirnia, Department of Psychology, Faculty of Humanities, University of Science and Culture, Tehran, Iran. Tel: +98.22081450, Email: b.pirnia@usc.ac.ir

Received: October 12, 2016, Accepted: February 02, 2017, Published: July 2017

iThenticate screening: January 09, 2017, English editing: March 04, 2017, Quality control: May 02, 2017

(C) 2017 The Authors. This is an open access article under the terms of the Creative Commons Attribution-NonCommercialNoDerivs License, which permits use and distribution in any medium, provided the original work is properly cited, the use is non-commercial and no modifications or adaptations are made. 


\section{Introduction}

Studies have shown that drugs with a capability of returning hemostat glutamate have been known as potential remedies of cocaine-dependence (1-3). Topiramate (TPM) is a kind of anticonvulsant drug which, in 1996, was suggested by the FDA as a curing drug of adults' convulsions and can have a significant role in neurological and psychiatric disorders. Topiramate facilitates gamma amino butyric acid (GABA) transference and prevents glutamates transference, where this process can reduce the cocaine reinforcing effect, and can be used in management of cocaine reliance (4). This drug increases central surfaces of GABA and potential acts of its absorbers, and is an antagonist attractor of AMPA in glycine. Topiramate reduces the presynaptic secretion of glutamate (5). There is an assumption that convulsion can be accounted as a running mechanism in addiction. Therefore, anticonvulsant drugs are counted as suitable candidates for intervention in the addiction domain of cocaine reliance (6). Although the research findings of efficacy of this drug remedy are contradictive, topiramate is an ideal candidate to increase avoidance in cocaine users (7). In an introductory study over men relying on cocaine, topiramate increased the avoidance period for twice the time the placebo did (8). Despite the efficacy of topiramate in reducing cocaine usage, this drug had most application in multi-users of methadone-cocaine. Also, this drug has its own usages for other misused narcotics like reporting of hopeful results of decrease in alcohol use (9-11), decreasing the extent of returning to alcohol usage after toxic removal (12), improving quitting smoking in men (13), curing of chronic pain (14), aggression (15-17) and obsession disorder (18). In a randomly controlled and closed experiment over cocaine and alcohol users, 20 percent of those participants that used 300 milligrams of topiramate daily, during the last three weeks showed cocaine avoidance in comparison to the 7 percent who received placebo (19). In another controlled study, significant efficacy of using 300 milligrams of topiramate daily in remedy of cocaine reliance was observed. In this study topiramate users showed $16.6 \%$ cocaine avoidance against $5.8 \%$ cocaine avoidance of placebo users (20).

In comparison studies, we also observed the efficacy of this drug in studies over animals. Topiramate in mice caused reduction of ethanol usage in a selection test of two bottles (21), decrease of alcohol intake (22), and reduction in signs of avoidance after remedy of chronic ethanol (23). However, some of the studies state the inefficacy or little efficacy of this drug. In a study of Ambridge et al. (23) topiramate didn't have any significant difference in reducing cocaine usage in methadone-cocaine combined users in comparison to placebo. In another study, prescription of 200 milligrams of topiramate daily, failed in increasing the avoidance period of methamphetamine; however, in a secondary analysis, the average level of meth of urine in a sample of topiramate group showed significant reduction (24). Also, this drug has been used for reduction of cocaine craving. In a study of Reis et al. (63), topiramate could reduce avidity intensity and usage period during the out-patience remedy of cocaine users. Kampman et al. (8) showed topiramate could increase the period of cocaine avoidance in comparison to the placebo group. One of the modern therapies with approved and tested clinical efficacy in the realm of drug abuse is contingency management (CM) therapy. Theoretical foundation of this remedy has a behaviorist basis and relies on conditioning the subject. Conditional management remedy, shapes behavior in form of using secondary positive boosters such as coupons, goods and services. In order to obtain useful remedial response, most of the reinforcement programs change during the management period (25). Contingency management is highly supported by clinical experiments (26, 27) and is successfully applied to a wide range of behavior such as adherence to therapy, losing weight and quitting smoking (28-31). Also, the researchers used this approach to improve behavioral objectives in many various communities (32-34). One of the most applicable domains of conditional management remedy is the domain of drug abuse where it has been explored greatly, and its advantage with a wide range of drugs (stimulants, alcohol, marijuana, tobacco) in various occasions (bedridden, outpatient inspection) has been approved (26, 33-36). One of the positive points of contingency management is its capability of focusing on the behavior of a specific target $(32,37-39)$. In contrast, for the weak points of contingency management, we can refer to ignorance of target behavior in conditions when the reinforcement does not continue for a long time $(40,41)$. According to the research literature, the remedial period of conditional management varies from 5 days (42) to 2 or 3 years (41). Furthermore the efficacy of contingency management approach for avoidance of wide range of drugs including benzodiazepines (43), nicotine (44), opioids $(45,46)$, marijuana $(47,48)$ and methamphetamines $(49,50)$ has been shown. CM has shown many times its usefulness in usage reduction of cocaine: therefore, we intend in this study, to explore the efficacy of the respective remedy on reduction of avid usage of cocaine in form of a controlled clinical experiment. Hence, we intend to study the effectiveness of the topiramate treatment, contingency management and combination of these two treatment groups compared to the placebo. 


\section{Material and Methods}

\subsection{Trial design and participants}

This study was a randomized clinical trial that was conducted from December 15, 2014 to November 20, 2015. This randomized clinical trial was conducted at Bijan Center for Substance Abuse Treatment in Tehran, Iran. The population of this study included the entire cocaine-dependent males during abstinence who were residents of Tehran, Iran. In conducting this study, one doctor, one psychiatrist, one clinical psychologist and one nurse cooperated. The data of this research were collected by using clinical interviews and self-reported questionnaires.

\subsection{Selection criteria}

The inclusion criteria for participation in this study were: 1) having the respective age between 18 and 31,2) history of one month of cocaine avoidance, and 3) having at least the educational level of a high school diploma. Also, the exclusion criteria were: 1) report of positive urine test during remedial period, 2) taking supplementary drug and psychological remedies, and 3) three continuous weeks of absence from participation in remedial meetings.

\subsection{Interventions}

One hundred and nine $(\mathrm{n}=109)$ men were selected from among the population based on voluntary participation. After informed consent was obtained, 100 participants were randomly divided and assigned into four groups (each group 25 persons), group 1, (topiramate), 2, (contingency management) 3, (the combination of Topiramate and contingency management) and 4, (placebo control). In addition, all subjects received brief behavioral compliance enhancement treatment (BBCET). All the topiramate capsules together with monohydrate lactose powder were provided less than sixty days before usage. Lactose was combined with 5 PPM denatonium benzoate to assimilate the bitter taste of all the capsules (similar to placebo). Both types of capsules were opaque and were of the same size of 550 milligrams. The 200 milligrams base dose topiramate was used in this study with regard to rear side effects of dosage of lower than 400 milligrams per day reported of this drug in clinical studies. Topiramate dosage was increased every third day until half of the remedy and the daily usage was divided into two dosages of morning and afternoon. The urine test band was randomly used to study cocaine metabolite in the first four weeks in the form of two weekly evaluations and after that, once every fifteen days. The validity of the samples was controlled by studying urine temperature, creatinine and $\mathrm{PH}$ and threshold of 300 Nano grams per milliliter was used for the urine analysis. Participants in the Cash-Based CM Condition had an identical 12-week escalating schedule of reinforcement. For groups, a specially designed computer program was utilized to maintain a record of all participants' urine results and the earned rewards. Prizes were exchanged with the aim of exchange of goods, services and improvement of social and sound behavior (25). The values of boosters in this study were three thousand, fifteen thousand and thirty thousand (about 1, 5 and 10 dollars respectively). Payments in this program were at most, 550 dollars (to each group), and were similar to other remedial programs $(51,52)$. The total cost of boosters during the period of three month was 1,200 dollars. The urine test band was used to investigate cocaine metabolite over four weeks in the form of two weekly evaluations and then used randomly one time every fifteen days, and the validity of the samples controlled by studying urine temperature, creatinine and PH and the threshold of 300 Nano grams in milliliter was considered for urine analysis. For negative urine samples (urine shortage of cocaine) a coupon was specified. Rewards for negative urine test of metabolite cocaine in the first sample was 1 dollar, for the second sample was 3 dollars, and for the third negative test was considered 5 dollars and in the next stages 1.25 dollars was added to the reward value, which after the urine negative test report, was given to the participants. Coupons began as one dollar for each urine sample without stimulant and increased at most, to 20 dollars. The inspections of subject urines were done two days per week from 10 a.m. to 6 p.m. After inspection of tests, participants were motivated to continue to take part in the study by email. All of the participants signed a contract in terms of expectations of remedial program (27). Also, urine samples were taken from the control group during the remedy to make sure the commitment of subjects to usage avoidance, but no coupons were devoted to them. After a passage of twelve remedial sessions, all the participants of the study for the second time, but this time in form of a posttest, were evaluated through the questionnaire of cocaine avid usage.

\subsection{Outcomes}

The primary outcomes of our analyses were the twelve weekly urine drug screens (detection of benzoylecgonine). Also, the secondary outcomes from the analyses were the cocaine craving.

\subsection{Sample size}

The sample size was calculated to be 100 subjects. In this study, with regard to one-way direction of hypothesis and assumption of $\mathrm{Z}=1.645, \mathrm{~d}=0.2, \alpha=0.05$ and also power of test $1-\beta=0.84$. 


\subsection{Randomization and blinding}

In this clinical trial, in the first step, 109 participants registered for participation in the study. Some time after the beginning of the study (between third week and ninth week), nine persons were removed from the study because of many reasons such as absence from remedial sessions and report of positive urine test. 100 participants were randomized to three groups (25 persons in each group) of experimental and one control group through IBM SPSS Statistics Version 20 (IBM Corp., Armonk, NY, USA) (random number generation).

\subsection{Statistical methods}

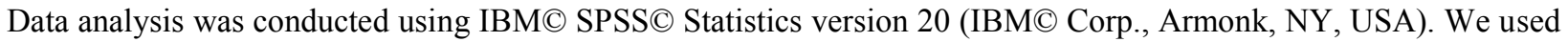
descriptive statistics, Chi square, ANCOVA Univariate Model and Scheffe's post hoc to analyze the primary and secondary outcomes. Also, before performing the statistical analyses, the normality of the variables' distribution was examined using the K-S test. Moreover, the qualitative data, resulted from demographic evaluations, were coded and analyzed by instrument of analysis of qualitative data i.e. Atlas.ti, Version 5.2.

\subsection{Research ethics}

In this study, the informed consent in their native language (Persian) was obtained prior to the study without coercion, threat, enticement and seduction and their decision to refuse or accept participation in the study were respected. It was also stated that the research methods do not contradict with the religious and cultural principles of the participants, and the participants were respected in all stages of design, implementation and reporting in terms of human dignity, respect and protection of their physical and mental integrity, so that conducting the research would not delay the process of medical care for the participants.

\subsection{Instruments and tests}

In this study, structured clinical interview, demographic researcher-made questionnaire, Cocaine Craving Questionnaire and Urine sample test were used.

2.9.1. Structured clinical interview for disorders (SCID):

It is a clinical interview which is used for distinguishing axis-one disorders based on DSM-IV. The final coefficient for measures of SCID was reported as 0.60 (53). The identification agreement of this instrument in Persian language was useful for most of the special and general determinations, with reliability of higher than 0.60 . Copa coefficient for all current determinations and determination of lifetime were 0.52 and 0.55 respectively (54).

2.9.2. Demographic questionnaire:

It is made by the researcher with the aim of applying and collecting individual information such as age, education, marriage status, employment and the period of drug usage.

\subsubsection{Cocaine Craving Questionnaire:}

It was designed by Tiffany et al. (55) The abridged version of it includes 10 statements that its psychometric features were investigated by Sussner et al. (56) on a sample including 247 cocaine users. The correlation of this index with Beck's depression index 0.39, anxiety index 0.35 and with recent use of drugs, 0.26 was reported. Also, the correlation of abridged form with original form of questionnaire was estimated at 0.85 and the internal reliability of this measure according to Corn Bache alpha was estimated 0.90.

2.9.4. Urine sample test:

Twelve weekly urine tests were taken by the addiction kit (cocaine).

\section{Results}

Table 1 shows the demographic state of the participants of the study. Most of the subjects have an educational level higher than Diploma (topiramate: 64\%, contingency management: $64 \%$, mix: $52 \%$, control: $64 \%$ ). Regarding the age index, most of the participants have the age index of older than 25 (topiramate: $52 \%$, contingency management: 64\%, mix: $52 \%$, control: $72 \%$ ). Distribution of participants in employment status index revealed that most of the subjects (topiramate: $52 \%$, contingency management: $60 \%$, mix: $56 \%$, control: $52 \%$ ) were employed. With regard to financial status too, most of the participants in four groups have an income of lower than 200 dollars per month (topiramate: $84 \%$, contingency management: $68 \%$, mix: $60 \%$, control: $72 \%$ ). According to Table 2 , the calculation of Leven statistics to study the equality of the respective variances, represents the lack of meaningfulness of this index. Therefore, use of statistical covariance analysis to compare two groups is possible. On the other hand, the results of independent t-test represent lack of meaningfulness of the scores of control and experimental groups in pretest stage. In Table 3, the mean and standard deviation of scores of cocaine craving is shown. The mean $(95 \% \mathrm{CI})$ scores of craving was $12.04(8.25-15.79, \mathrm{p}=0.05)$ with TPM, $13.89(10.48-17.3, \mathrm{p}=0.05)$ with CM, 10.92 (3.19- 
16.03, $\mathrm{p}=0.01)$ with mix and 16.89 (11.03-21.95) with control. Based on the results of covariance analysis test, between the average of posttests of groups, a significant difference was observed $(\mathrm{F}=13.571, \mathrm{p}<0.01)$. The Scheffe's post hoc test was used in order to compare the groups in terms of the mean scores of the craving index. The results showed that all three types of treatment played a significant efficacy in reducing the craving. Moreover, the highest variance explaining the changes in craving was assigned to the combined treatment $(p<0.01)$.

Table 1. Demographic characteristics of the participants

\begin{tabular}{|l|l|l|l|l|l|}
\hline Variable & Index & TPM; n (\%) & CM; n (\%) & MIX; n (\%) & Control; n (\%) \\
\hline Education level & $<$ High school diploma & $9(36)$ & $11(44)$ & $12(48)$ & $9(36)$ \\
\cline { 2 - 6 } & $>$ High school diploma & $16(64)$ & $14(56)$ & $13(52)$ & $16(64)$ \\
\hline \multirow{2}{*}{ Age (year) } & $18-25$ & $12(48)$ & $9(36)$ & $12(48)$ & $7(28)$ \\
\cline { 2 - 6 } & $>25$ & $13(52)$ & $16(64)$ & $13(52)$ & $18(72)$ \\
\hline \multirow{2}{*}{ Employment status } & Employed & $13(52)$ & $15(60)$ & $14(56)$ & $13(52)$ \\
\cline { 2 - 6 } & Unemployed & $12(48)$ & $10(40)$ & $11(44)$ & $12(48)$ \\
\hline \multirow{2}{*}{ Monthly income (U.S. dollar) } & $<200$ & $21(48)$ & $17(68)$ & $15(60)$ & $13(52)$ \\
\cline { 2 - 6 } & $>200$ & $4(16)$ & $8(32)$ & $10(40)$ & $12(48)$ \\
\hline
\end{tabular}

Table 2. Variance equality test about research variables

\begin{tabular}{|l|l|l|}
\hline Group & Levene's test & Sig. \\
\hline TPM & 0.589 & 0.764 \\
\hline CM & 0.668 & 0.326 \\
\hline MIX & 0.484 & 0.260 \\
\hline CONTROL & 0.561 & 0.786 \\
\hline
\end{tabular}

Table 3. The Mean and Standard deviation

\begin{tabular}{|l|l|l|}
\hline Group & Pretest; mean (SD) & Posttest; mean (SD) \\
\hline TPM & $14.84(3.12)$ & $12.04(2.29)$ \\
\hline CM & $13.90(2.83)$ & $13.89(2.08)$ \\
\hline MIX & $15.81(2.03)$ & $10.92(3.12)$ \\
\hline Control & $17.31(3.49)$ & $16.89(3.09)$ \\
\hline
\end{tabular}

\section{Discussion}

The present study aimed to evaluate and compare three medication methods of Topiramate (TPM), Contingency Management (CM) and the Combined Method on the index of craving in cocaine-dependent patients in abstinence phase. The results of the present study showed that all three types of treatment played a significant efficacy in reducing the craving. Moreover, the highest variance explaining the changes in craving was assigned to the combined treatment. Hence, we intend to study the effectiveness of the topiramate treatment, contingency management and combination of these two treatments groups compared to the placebo. Moreover, most of the variance explaining the changes in craving was assigned to combination therapy. The findings are consistent with the findings of a number of previous studies. In a Johnson et al. (20) study, prescription of 300 milligram topiramate per day was reported effective in remedy of cocaine reliance. Also prescription of 200 milligrams of topiramate per day significantly decreased the met-amphetamine level of urine (24). In a meta-analysis of five studies of which four of them were done with placebo and one without placebo, the respective effects of topiramate were compared. In two studies of five studies, topiramate had significant efficacy in regular avoidance duration index. Also in one of the five studies, topiramate had significant efficacy on reduction of cocaine craving (57). On the other hand, findings of some of the comparative studies represented the efficacy of topiramate in alcohol usage. The efficacy of topiramate represented in ethanol usage both in mice which were selected based on above usage and in trained mice (58-60). It must be noted that some of the research findings contradicted with finding of this study, confirm the inefficacy of this drug in treatment of addiction, for example, in a meta-analysis (61), no definite results were observed regarding the efficacy of topiramate in remedy of cocaine, amphetamine, cannabis and nicotine. However, the efficacy of the above remedy in curing of calcium and bulimia nervosa was reported. In a study (62), the effect of topiramate with and without behaviorist intervention was investigated in people who relied on cocaine. The results showed that remedy with topiramate has limited capability in cocaine users and also the extent of remedy acceptation and commitment to remedy was low in respective people. In another study, topiramate failed to induce avoidance in methamphetamine users, but had significant efficacy in decreasing the extent of stumbling in quitting 
people (24). On the other hand, in a meta-analysis, no significant difference was observed between anticonvulsant topiramate and placebo. The literature review shows that topiramate reduces avid usage in cocaine users (63). Through a super analysis during 1991 to 2004, Lussier et al. (34) showed that use of CM had been significantly effective in reducing the drug usage. Prendergast et al. (33) considered CM effective in the domain of drug abuse. On the other hand, in a study of Kirby et al. (64), CM caused drug avoidance in cocaine users but sustaining this avoidance after enough remedy was not reported. In another study, Festinger et al. (65) investigated the efficacy of $\mathrm{CM}$ in the extent of avid usage in people dependent on cocaine and reported this efficacy as positive. In another study, Preston et al. (66) reported that contingency management remedy could reduce avid heroine usage. In a study by Pirnia et al. (67), contingency management was associated with reduction of usage craving in cocaine-dependent individuals in abstinence. On the other hand, part of the results of this study showed that combining the two methods of topiramate treatment and contingency management had significant efficacy in reducing the craving for cocaine. Although no similar study was found in this regard in the PUBMED database, , there have been several studies to examine the efficacy of the combination of the pharmacological and psychological treatment. In the study conducted by Kim and Lawrence (68), the efficacy of topiramate in the treatment of cocaine dependence was reported close to the effectiveness of cognitive behavioral therapy, and the integration of both treatments was suggested to enhance abstinence. In a study by Poling et al. (69), a combination of contingency management and Bupropion were studied. The results showed that the combination of two treatments had better efficacy than the Buprenorphine treatment alone. This study had some limitations. The most important limitations were as follow: 1) the cross-sectional nature of the study, limits the overall conclusion and comprehensive forecast; and 2) using a self-report assessment in sensitive subjects often causes to create a favorable social image and causes the bias to appear. In order to conduct more accurate assessments, it is recommended that neuropsychological tools are used in addition to the questionnaires. It is recommended that a same sample of females should be used in future studies, an indication that its assessment was not possible in the present study.

\section{Conclusions}

The study is an experimental and independent research in the area. The population of this study included entirely cocaine-dependent males in the abstinence phase. The results showed that all three types of treatment played a significant efficacy in reducing the craving. Moreover, the highest variance explaining the changes in craving was assigned to the combined treatment. Hence, we intend to study the effectiveness of the topiramate treatment, contingency management and combination of these two treatment groups compared to the placebo. These findings could offer hope to evoke a therapeutic approach and will be promising for medical and behavioral science.

\section{Acknowledgments:}

All those who have participated in this study and helped in facilitating this research process, especially management and personnel of Bijan Addiction Center, are appreciated.

\section{Trial registration:}

The trial was registered at the Thai Clinical Trial Registration Center with the TCR ID: TCTR20170112001.

\section{Funding:}

The authors received no financial support for the research, authorship, and/or publication of this article.

\section{Conflict of Interest:}

There is no conflict of interest to be declared.

Authors' contributions:

All authors contributed to this project and article equally. All authors read and approved the final manuscript.

\section{References:}

1) Moran MM, McFarland K, Melendez RI, Kalivas PW, Seamans JK. Cystine/glutamate exchange regulates metabotropic glutamate receptor presynaptic inhibition of excitatory transmission and vulnerability to cocaine seeking. J Neurosci. 2005; 25(27): 6389-93. doi: 10.1523/JNEUROSCI.1007-05.2005. PMID: 16000629, PMCID: PMC1413952.

2) Peters J, LaLumiere RT, Kalivas PW. Infralimbic prefrontal cortex is responsible for inhibiting cocaine seeking in extinguished rats. J Neurosci. 2008; 28(23): 6046-53. doi: 10.1523/JNEUROSCI.1045-08.2008. PMID: 18524910, PMCID: PMC2585361. 
3) Kalivas PW. The glutamate homeostasis hypothesis of addiction. Nat Rev Neurosci. 2009; 10(8): 561-72. doi: 10.1038/nrn2515. PMID: 19571793.

4) Siniscalchi A, Bonci A, Biagio Mercuri N, Pirritano D, Squillace A, De Sarro G, et al. The Role of Topiramate in the Management of Cocaine Addiction: a Possible Therapeutic Option. Curr Neuropharmacol. 2015; 13(6): 815-8. doi: 10.2174/1570159x13666150729222643. PMID: 26630959, PMCID: PMC4759320.

5) Alves OL, Doyle AJ, Clausen T, Gilman C, Bullock R. Evaluation of topiramate neuroprotective effect in severe TBI using microdialysis. Ann N Y Acad Sci. 2003; 993: 25-34. doi: 10.1111/j.17496632.2003.tb07508.x. PMID: 12853292.

6) Minozzi S, Amato L, Davoli M, Farrell M, Lima Reisser AA, Pani PP, et al. Anticonvulsants for cocaine dependence. Cochrane Database Syst Rev. 2008; (2): CD006754. doi: 10.1002/14651858.CD006754.pub2. PMID: 18425968.

7) Vocci F, Ling W. Medications development: successes and challenges. Pharmacology \& therapeutics. 2005; 108(1): 94-108. doi: 10.1016/j.pharmthera.2005.06.010. PMID: 16083966.

8) Kampman KM, Pettinati H, Lynch KG, Dackis C, Sparkman T, Weigley C, et al. A pilot trial of topiramate for the treatment of cocaine dependence. Drug Alcohol Depend. 2004; 75(3): 233-40. doi: 10.1016/j.drugalcdep.2004.03.008. PMID: 15283944.

9) Johnson BA. Recent advances in the development of treatments for alcohol and cocaine dependence: focus on topiramate and other modulators of GABA or glutamate function. CNS Drugs. 2005; 19(10): 873-96. doi: 10.2165/00023210-200519100-00005. PMID: 16185095.

10) Johnson BA, Ait-Daoud N, Bowden CL, DiClemente CC, Roache JD, Lawson K, et al. Oral topiramate for treatment of alcohol dependence: a randomised controlled trial. Lancet. 2003; 361(9370): 1677-85. doi: 10.1016/S0140-6736(03)13370-3. PMID: 12767733.

11) Baltieri DA, Daró FR, Ribeiro PL, De Andrade AG. Comparing topiramate with naltrexone in the treatment of alcohol dependence. Addiction. 2008; 103(12): 2035-44. doi: 10.1111/j.1360-0443.2008.02355.x. PMID: 18855810.

12) Rubio G, Martínez-Gras I, Manzanares J. Modulation of impulsivity by topiramate: implications for the treatment of alcohol dependence. J Clin Psychopharmacol. 2009; 29(6): 584-9. doi: 10.1097/JCP.0b013e3181bfdb79. PMID: 19910725.

13) Anthenelli RM, Blom TJ, McElroy SL, Keck PE Jr. Preliminary evidence for gender - specific effects of topiramate as a potential aid to smoking cessation. Addiction. 2008; 103(4): 687-94. doi: 10.1111/j.13600443.2008.02148.x. PMID: 18339115.

14) Khoromi S, Patsalides A, Parada S, Salehi V, Meegan JM, Max MB. Topiramate in chronic lumbar radicular pain. J Pain. 2005; 6(12): 829-36. doi: 10.1016/j.jpain.2005.08.002. PMID: 16326371.

15) Nickel MK, Nickel C, Kaplan P, Lahmann C, Mühlbacher M, Tritt K, et al. Treatment of aggression with topiramate in male borderline patients: a double-blind, placebo-controlled study. Biol Psychiatry. 2005; 57(5): 495-9. doi: 10.1016/j.eurpsy.2007.09.004. PMID: 15737664.

16) Nickel C, Lahmann C, Tritt K, Muehlbacher M, Kaplan P, Kettler C, et al. Topiramate in treatment of depressive and anger symptoms in female depressive patients: a randomized, double-blind, placebocontrolled study. J Affect Disord. 2005; 87(2-3): 243-52. doi: 10.1016/j.jad.2005.04.003. PMID: 15985295.

17) Nickel MK, Nickel C, Mitterlehner FO, Tritt K, Lahmann C, Leiberich PK, et al. Topiramate treatment of aggression in female borderline personality disorder patients: a double-blind, placebo-controlled study. J Clin Psychiatry. 2004; 65(11): 1515-9. doi: 10.4088/jcp.v65n1112. PMID: 15554765.

18) Van Ameringen M, Mancini C, Patterson B, Bennett M. Topiramate augmentation in treatment - resistant obsessive - compulsive disorder: a retrospective, open - label case series. Depress Anxiety. 2006; 23(1): 15. doi: 10.1002/da.20118. PMID: 16178009.

19) Kampman KM, Pettinati HM, Lynch KG, Spratt K, Wierzbicki MR, O’Brien CP. A double-blind, placebocontrolled trial of topiramate for the treatment of comorbid cocaine and alcohol dependence. Drug Alcohol Depend. 2013; 133(1): 94-9. doi: 10.1016/j.drugalcdep.2013.05.026. PMID: 23810644, PMCID: PMC3786029.

20) Johnson BA, Ait-Daoud N, Wang XQ, Penberthy JK, Javors MA, Seneviratne C, et al. Topiramate for the treatment of cocaine addiction: a randomized clinical trial. JAMA psychiatry. 2013; 70(12): 1338-46. doi: 10.1001/jamapsychiatry.2013.2295. PMID: 24132249. 
21) Knapp CM, Mercado M, Markley TL, Crosby S, Ciraulo DA, Kornetsky C. Zonisamide decreases ethanol intake in rats and mice. Pharmacol Biochem Behav. 2007; 87(1): 65-72. doi: 10.1016/j.pbb.2007.04.001. PMID: 17482246, PMCID: PMC2867456.

22) Hargreaves GA, McGregor IS. Topiramate moderately reduces the motivation to consume alcohol and has a marked antidepressant effect in rats. Alcohol Clin Exp Res. 2007; 31(11): 1900-7. doi: 10.1111/j.15300277.2007.00485.x. PMID: 17877781.

23) Cagetti E, Baicy KJ, Olsen RW. Topiramate attenuates withdrawal signs after chronic intermittent ethanol in rats. Neuroreport. 2004; 15(1): 207-10. doi: 10.1097/00001756-200401190-00040. PMID: 15106859.

24) Elkashef A, Kahn R, Yu E, Iturriaga E, Li SH, Anderson A, et al. Topiramate for the treatment of methamphetamine addiction: a multi - center placebo - controlled trial. Addiction. 2012; 107(7): 1297306. doi: 10.1111/j.1360-0443.2011.03771.x. PMID: 22221594, PMCID: PMC3331916.

25) Higgins ST, Budney AJ, Bickel WK, Foerg FE, Donham R, Badger GJ. Incentives improve outcome in outpatient behavioral treatment of cocaine dependence. Arch Gen Psychiatry. 1994; 51(7): 568-76. doi: 10.1001/archpsyc.1994.03950070060011. PMID: 8031230.

26) Griffith JD, Rowan-Szal GA, Roark RR, Simpson DD. Contingency management in outpatient methadone treatment: a meta-analysis. Drug Alcohol Depend. 2000; 58(1-2): 55-66. doi: 10.1016/s03768716(99)00068-x. PMID: 10669055.

27) Petry NM, Martin B, Cooney JL, Kranzler HR. Give them prizes and they will come: Contingency management for treatment of alcohol dependence. J Consult Clin Psychol. 2000; 68(2): 250-7. doi: 10.1037/0022-006x.68.2.250. PMID: 10780125.

28) Schepis TS, Duhig AM, Liss T, McFetridge A, Wu R, Cavallo DA, et al. Contingency management for smoking cessation: Enhancing feasibility through use of immunoassay test strips measuring cotinine. Nicotine Tob Res. 2008; 10(9): 1495-501. doi: 10.1080/14622200802323209. PMID: 19023841, PMCID: PMC3679884.

29) Volpp KG, John LK, Troxel AB, Norton L, Fassbender J, Loewenstein G. Financial incentive-based approaches for weight loss: a randomized trial. Jama. 2008; 300(22): 2631-7. doi: 10.1001/jama.2008.804. PMID: 19066383, PMCID: PMC3583583.

30) Volpp KG, Loewenstein G, Troxel AB, Doshi J, Price M, Laskin M, et al. A test of financial incentives to improve warfarin adherence. BMC Health Serv Res. 2008; 8: 272. doi: 10.1186/1472-6963-8-272. PMID: 19102784, PMCID: PMC2635367.

31) Volpp KG, Troxel AB, Pauly MV, Glick HA, Puig A, Asch DA, et al. A randomized, controlled trial of financial incentives for smoking cessation. N Engl J Med. 2009; 360(7): 699-709. doi: 10.1056/NEJMsa0806819. PMID: 19213683.

32) Petry NM, Tedford J, Martin B. Reinforcing compliance with non-drug-related activities. J Subst Abuse Treat. 2001; 20(1): 33-44. doi: 10.1016/s0740-5472(00)00143-4. PMID: 11239726.

33) Prendergast M, Podus D, Finney J, Greenwell L, Roll J. Contingency management for treatment of substance use disorders: A meta - analysis. Addiction. 2006; 101(11): 1546-60. doi: 10.1111/j.13600443.2006.01581.x. PMID: 17034434.

34) Lussier JP, Heil SH, Mongeon JA, Badger GJ, Higgins ST. A meta - analysis of voucher - based reinforcement therapy for substance use disorders. Addiction. 2006; 101(2): 192-203. doi: 10.1111/j.13600443.2006.01311.x. PMID: 16445548.

35) Stitzer ML, Vandrey R. Contingency management: utility in the treatment of drug abuse disorders. Clin Pharmacol Ther. 2008; 83(4): 644-7. doi: 10.1038/sj.clpt.6100508. PMID: 18305456.

36) Peirce JM, Petry NM, Stitzer ML, Blaine J, Kellogg S, Satterfield F, et al. Effects of lower-cost incentives on stimulant abstinence in methadone maintenance treatment: A National Drug Abuse Treatment Clinical Trials Network study. Arch Gen Psychiatry. 2006; 63(2): 201-8. doi: 10.1001/archpsyc.63.2.201. PMID: 16461864.

37) Carroll KM, Ball SA, Nich C, O'Connor PG, Eagan DA, Frankforter TL, et al. Targeting behavioral therapies to enhance naltrexone treatment of opioid dependence: efficacy of contingency management and significant other involvement. Arch Gen Psychiatry. 2001; 58(8): 755-61. doi: 10.1001/archpsyc.58.8.755. PMID: 11483141, PMCID: PMC3651594.

38) Carroll KM, Sinha R, Nich C, Babuscio T, Rounsaville BJ. Contingency management to enhance naltrexone treatment of opioid dependence: a randomized clinical trial of reinforcement magnitude. Exp Clin Psychopharmacol. 2002; 10(1): 54-63. doi: 10.1037/1064-1297.10.1.54. PMID: 11866252. 
39) Preston KL, Silverman K, Umbricht A, DeJesus A, Montoya ID, Schuster CR. Improvement in naltrexone treatment compliance with contingency management. Drug Alcohol Depend. 1999; 54(2): 127-35. doi: 10.1016/s0376-8716(98)00152-5. PMID: 10217552.

40) Marlatt GA. Integrating contingency management with relapse prevention skills: Comment on Silverman et al. Exp Clin Psychopharmacol. 2001; 9(1): 33-4. doi: 10.1037/1064-1297.9.1.33. PMID: 11519633.

41) Silverman K, Svikis D, Wong CJ, Hampton J, Stitzer ML, Bigelow GE. A reinforcement-based therapeutic workplace for the treatment of drug abuse: three-year abstinence outcomes. Exp Clin Psychopharmacol. 2002; 10(3): 228-40. doi: 10.1037/1064-1297.10.3.228. PMID: 12233983.

42) Corby EA, Roll JM, Ledgerwood DM, Schuster CR. Contingency management interventions for treating the substance abuse of adolescents: a feasibility study. Exp Clin Psychopharmacol. 2000; 8(3): 371-6. doi: 10.1037/1064-1297.8.3.371. PMID: 10975628.

43) Stitzer ML, Bigelow GE, Liebson I. Reducing benzodiazepine self-administration with contingent reinforcement. Addict Behav. 1979; 4(3): 245-52. doi: 10.1016/0306-4603(79)90034-0. PMID: 495248.

44) Stitzer ML, Rand CS, Bigelow GE, Mead AM. Contingent payment procedures for smoking reduction and cessation. J Appl Behav Anal. 1986; 19(2): 197-202. doi: 10.1901/jaba.1986.19-197. PMID: 3733589, PMCID: PMC1308058.

45) Higgins ST, Stitzer ML, Bigelow GE, Liebson IA. Contingent methadone delivery: Effects on illicit-opiate use. Drug Alcohol Depend. 1986; 17(4): 311-22. doi: 10.1016/0376-8716(86)90080-3. PMID: 3757767.

46) Robles E, Stitzer ML, Strain EC, Bigelow GE, Silverman K. Voucher-based reinforcement of opiate abstinence during methadone detoxification. Drug and alcohol dependence. 2002; 65(2): 179-89. doi: 10.1016/s0376-8716(01)00160-0. PMID: 11772479.

47) Budney AJ, Higgins ST, Radonovich KJ, Novy PL. Adding voucher-based incentives to coping skills and motivational enhancement improves outcomes during treatment for marijuana dependence. J Consult Clin Psychol. 2000; 68(6): 1051-61. doi: 10.1037/0022-006x.68.6.1051. PMID: 11142539.

48) Sigmon SC, Steingard S, Badger GJ, Anthony SL, Higgins ST. Contingent reinforcement of marijuana abstinence among individuals with serious mental illness: A feasibility study. Exp Clin Psychopharmacol. 2000; 8(4): 509-17. doi: 10.1037/1064-1297.8.4.509. PMID: 11127422.

49) Rawson RA, Gonzales R, Brethen P. Treatment of methamphetamine use disorders: an update. J Subst Abuse Treat. 2002; 23(2): 145-50. doi: 10.1016/s0740-5472(02)00256-8. PMID: 12220612.

50) Roll JM, Petry NM, Stitzer ML, Brecht ML, Peirce JM, McCann MJ, et al. Contingency management for the treatment of methamphetamine use disorders. Am J Psychiatry. 2006; 163(11): 1993-9. doi: 10.1176/ajp.2006.163.11.1993. PMID: 17074952.

51) Shoptaw S, Klausner JD, Reback CJ, Tierney S, Stansell J, Hare CB, et al. A public health response to the methamphetamine epidemic: the implementation of contingency management to treat methamphetamine dependence. BMC public health. 2006; 6: 214. doi: 10.1186/1471-2458-6-214. PMID: 16919170, PMCID: PMC1559698.

52) Strona FV, McCright J, Hjord H, Ahrens K, Tierney S, Shoptaw S, et al. The acceptability and feasibility of the Positive Reinforcement Opportunity Project, a community-based contingency management methamphetamine treatment program for gay and bisexual men in San Francisco. J Psychoactive Drugs. 2006; Suppl 3: 377-83. doi: 10.1080/02791072.2006.10400601. PMID: 17357529.

53) First M, Spitzer R, Gibbon M, Williams J. Biometrics Research. New York State Psychiatric Institute; New York: 2002. Structured Clinical Interview for DSM-IV-TR Axis I Disorders, Research Version, Patient Edition. Clinical Trials Version (SCID-CT).

54) Sharifi V, Assadi SM, Mohammadi MR, Amini H, Kaviani H, Semnani Y, et al. A Persian translation of the structured clinical interview for diagnostic and statistical manual of mental disorders: psychometric properties. Compr Psychiatry. 2009; 50(1): 86-91. doi: 10.1016/j.comppsych.2008.04.004. PMID: 19059520.

55) Tiffany ST, Singleton E, Haertzen CA, Henningfield JE. The development of a cocaine craving questionnaire. Drug Alcohol Depend. 1993; 34(1): 19-28. doi: 10.1016/0376-8716(93)90042-o. PMID: 8174499.

56) Sussner BD, Smelson DA, Rodrigues S, Kline A, Losonczy M, Ziedonis D. The validity and reliability of a brief measure of cocaine craving. Drug Alcohol Depend. 2006; 83(3): 233-7. doi: 10.1016/j.drugalcdep.2005.11.022. PMID: 16384655.

57) Singh M, Keer D, Klimas J, Wood E, Werb D. Topiramate for cocaine dependence: a systematic review and meta - analysis of randomized controlled trials. Addiction. 2016; 111(8): 1337-46. doi: 10.1111/add.13328. PMID: 26826006. 
58) Nguyen SA, Malcolm R, Middaugh LD. Topiramate reduces ethanol consumption by C57BL/6 mice. Synapse. 2007; 61(3): 150-6. doi: 10.1002/syn.20350. PMID: 17146766.

59) Breslin FJ, Johnson BA, Lynch WJ. Effect of topiramate treatment on ethanol consumption in rats. Psychopharmacology (Berl). 2010; 207(4): 529-34. doi: 10.1007/s00213-009-1683-4. PMID: 19823810, PMCID: PMC4142502.

60) Zalewska-Kaszubska J, Bajer B, Gorska D, Andrzejczak D, Dyr W, Bieńkowski P. Effect of repeated treatment with topiramate on voluntary alcohol intake and beta-endorphin plasma level in Warsaw alcohol high-preferring rats. Psychopharmacology (Berl). 2013; 225(2): 275-81. doi: 10.1007/s00213-012-2812-z. PMID: 22847457, PMCID: PMC3536943.

61) Cohen J, Dervaux A, Laqueille X. [Topiramate in substance-related and addictive disorders]. Presse Med. 2014; 43(9): 892-901. doi: 10.1016/j.1pm.2014.02.030. PMID: 25027463.

62) Nuijten M, Blanken P, van den Brink W, Hendriks V. Treatment of crack-cocaine dependence with topiramate: A randomized controlled feasibility trial in The Netherlands. Drug Alcohol Depend. 2014; 138: 177-84. doi: 10.1016/j.drugalcdep.2014.02.024. PMID: 24629631.

63) Reis AD, Castro LA, Faria R, Laranjeira R. Craving decrease with topiramate in outpatient treatment for cocaine dependence: an open label trial. Rev Bras Psiquiatr. 2008; 30(2): 132-5. doi: 10.1590/s151644462008005000012. PMID: 18470406.

64) Kirby KC, Carpenedo CM, Dugosh KL, Rosenwasser BJ, Benishek LA, Janik A, et al. Randomized clinical trial examining duration of voucher-based reinforcement therapy for cocaine abstinence. Drug Alcohol Depend. 2013; 132(3): 639-45. doi: 10.1016/j.drugalcdep.2013.04.015. PMID: 23680075, PMCID: PMC3770760.

65) Festinger DS, Dugosh KL, Kirby KC, Seymour BL. Contingency management for cocaine treatment: Cash vs. vouchers. Journal of substance abuse treatment. 2014; 47(2): 168-74. doi: 10.1016/j.jsat.2014.03.001. PMID: 24746956, PMCID: PMC4504189.

66) Preston KL, Ghitza UE, Schmittner JP, Schroeder JR, Epstein DH. Randomized trial comparing two treatment strategies using prize-based reinforcement of abstinence in cocaine and opiate users. J Appl Behav Anal. 2008; 41(4): 551-63. doi: 10.1901/jaba.2008.41-551. PMID: 19192859, PMCID: PMC2606600.

67) Pirnia B, Tabatabaei SK, Tavallaii A, Soleimani AA, Pirnia K. The Efficacy of Contingency Management on Cocaine Craving, using Prize-based Reinforcement of Abstinence in Cocaine Users. Electron Physician. 2016; 8(11): 3214-21. doi: 10.19082/3214. PMID: 28070254, PMCID: PMC5217813.

68) Kim JH, Lawrence AJ. Drugs currently in Phase II clinical trials for cocaine addiction. Expert Opin Investig Drugs. 2014; 23(8): 1105-22. doi: 10.1517/13543784.2014.915312. PMID: 24773297.

69) Poling J, Oliveto A, Petry N, Sofuoglu M, Gonsai K, Gonzalez G, et al. Six-month trial of bupropion with contingency management for cocaine dependence in a methadone-maintained population. Arch Gen Psychiatry. 2006; 63(2): 219-28. doi: 10.1001/archpsyc.63.2.219. PMID: 16461866. 